\title{
JOVENS E CIDADE: a experiência do projeto ArteUrbe
}

Youth and City: the experience of ArteUrbe project Juventud y Ciudad: la experiencia del proyeto ArteUrbe

\author{
Andréa Vieira Zanella \\ Universidade Federal de Santa Catarina, Florianópolis, SC, Brasil. \\ Renan De Vita Alves de Brito \\ Universidade Federal de Santa Catarina, Florianópolis, SC, Brasil.
}

\begin{abstract}
Resumo
A temática da cidade como espaço de constituição do sujeito vem se caracterizando como objeto de discussões em diferentes campos. O assunto é discutido neste texto via experiência de um projeto de pesquisa-intervenção alicerçado na oferta de oficinas estéticas para jovens com a mediação de linguagens artísticas da arte urbana. Foram analisadas as produções gráficas decorrentes das oficinas e os discursos dos jovens sobre a urbe. O referencial para análise foi a teoria histórico-cultural, a qual concebe toda e qualquer pessoa como ser constituído no contexto social do qual é parte e ativamente participa. Constatou-se que as cidades produzidas pelos jovens eram diferentes e únicas, divergentes das imagens da cidade veiculadas pela mídia. A reinvenção da urbe e de si mesmos via atividades estéticas afirmouse, por sua vez, como possibilidade no contexto das oficinas estéticas, configurando-as como espaços para a reinvenção das relações dos jovens com a cidade.
\end{abstract}

Palavras-chave: Cidade, Relações estéticas, Arte urbana.

\section{Resumen}

El tema de la ciudad como un lugar de la constitución del sujeto se caracteriza por ser objeto de discusión en diferentes campos. Este artículo presenta la experiencia de un proyecto de investigación-intervención basada en el taller de estética que ofrece para los jóvenes con la mediación de los lenguajes artísticos del arte urbano. Se analizaron las producciones gráficas de los talleres y los discursos de los jóvenes acerca de la urbe. El referencial de análisis fue la teoría histórico-cultural, que entiende todo y cualquier persona como un ser constituido en el contexto social en el que él pertenece y participa activamente. Se encontró que las ciudades producidos por los jóvenes era diferente y único, disonante de los medios de comunicación transmiten imágenes. Urbe y la propia reinvención a través de actividades estéticas se planteó 
como posibilidad en el contexto de talleres estéticos, el establecimiento de lugares como la reinvención de las relaciones con los jóvenes de la ciudad.

Palabras-clave: Ciudad, Relaciones estéticas, Arte urbano.

\begin{abstract}
The theme of city as a place of subject constitution is being characterized as object of discussion in different fields. This article presents the experience of a research-intervention project grounded in the aesthetic workshop offered for youths with mediation of artistic languages of urban art. It was analysed the graphic productions of the workshops and discourses of youths about the urbe. The analysis referencial was the historical-cultural theory, which understands every and any person as a being constituted in the social context in he belongs and actively participates. It was found that the cities produced by the youths it was different and unique, dissonant of the media conveyed images. Urbe's and self reinvention through aesthetic activities was raised as possibility in the aesthetic workshop contexts, setting them as reinvention places of the youth relations with the city.
\end{abstract}

Key-words: City, Aestethic relations, Urban art.

\section{Introdução}

Este artigo apresenta e discute o projeto de pesquisa/extensão ArteUrbe, direcionado a jovens que frequentam escolas do ensino publico de Florianópolis/SC. O projeto consistiu na oferta de oficinas estéticas que tinham por objetivo problematizar as relações dos jovens com a cidade e as possibilidades de sua (re)invenção por meio da arte. Realizadas entre abril e novembro de 2010 , as atividades do projeto consistiram em oficinas estéticas desenvolvidas com a mediação de variadas linguagens artísticas- visuais, a saber: fotografia, graffiti, estêncil e lambe-lambe. O uso dessas linguagens, no contexto das oficinas, tinha como eixo norteador sua inscrição na cidade.

$\mathrm{O}$ desenho do projeto fundamentouse no enfoque histórico-cultural em psicologia, o qual concebe toda e qualquer pessoa como ser constituído no contexto social do qual é parte/participa, sendo produto e produtora do lócus em que habita/transita. A partir dessa concepção, o projeto foi desenvolvido atentando para as relações dos jovens com a cidade e possíveis modificações nessas relações com a mediação da arte urbana. Essa 
escolha pautou-se na compreensão de que, "assim como em outros modos de arte, a arte urbana permite um momento de criação, porque o processo de percepção requer que o sujeito recrie o objeto e, partindo da sua forma e do seu significado, imponha a este sentidos próprios" (Furtado e Zanella, 2007, p. 318).

O processo de criação e produção de sentidos funda-se em relações estéticas, consideradas como uma maneira sensível do sujeito se relacionar com o mundo, que o provoca a modificar o modo como se posiciona em relação ao contexto e o significa:

[...] quando o sujeito contempla essa outra realidade que é exatamente a do objeto na situação estética, o humano como 'centro de gravidade' se desloca da 'realidade vivida' para outra, a estética, mais plena e profundamente humana. Existe, pois, uma dialética da união e da separação, da identificação e do distanciamento de sujeito e objeto que constitui a própria natureza de sua relação na situação estética. (Vázquez, 1978, p.152-153).

A partir da compreensão da importância das relações estéticas para a modificação das relações com os outros, com o contexto e consigo mesmo, pretendeu-se com este projeto de pesquisa/extensão possibilitar aos jovens vivências estéticas que engendrassem esse tipo de relação sensível com o contexto em que vivem, instigando-os a ler as inscrições estéticas e ao mesmo tempo inscreverem na cidade suas próprias marcas.

Justifica-se esta proposta a configuração das cidades modernas não possibilita aos seus habitantes, de certo modo, práticas de encontros sensíveis e de manifestações criativas. No cenário citadino há pessoas que, com poucas opções de escolha, transitam pelo seu próprio mundo, indo e vindo por ruas obscuras e solitárias, às vezes perdidos; não costumam pedir informações, e o vagar solitário é a marca desse transitar. Os caminhos se confundem no grande labirinto da subjetividade, como relata Ítalo Calvino:

Em Cloé, cidade grande, as pessoas que passam pelas ruas não se reconhecem. Quando se veem, imaginam mil coisas a respeito umas das outras, os encontros que poderiam ocorrer entre elas, as conversas, as surpresas, as carícias, as mordidas. Mas ninguém se cumprimenta, os olhares se cruzam por um segundo e depois se desviam, procurando outros olhares, não se fixam. (Calvino, 2008, p.51).

Acreditamos que essa condição de cidade passagem pode ser modificada, com 
intervenções que problematizem as relações que se estabelece com a urbe. Fazer os jovens perceberem que a própria cidade (seus muros, calçadas, postes, arquitetura) pode ser porta-voz de suas necessidades, pode narrar suas angústias e desejos, é um caminho para possibilitar relações mais sensíveis/estéticas com os espaços em que habitam.

As diferentes percepções e interpretações da cidade advindas de cada um de seus habitantes misturam-se às diferentes percepções que essas pessoas têm de si mesmas. As relações estabelecidas dentro do espaço urbano são de fundamental importância no desenvolvimento e constituição dos sujeitos que a habitam e, de certa forma, são termômetros para medir como essas pessoas estão se relacionado consigo mesmas.

Interações superficiais são, em certo ponto, uma característica dos processos de troca e funcionamento da cidade na atualidade. As cidades se ampliaram e se desenvolveram expressivamente nos últimos séculos em decorrência da industrialização. Cada vez mais, vêm adquirindo e conservando um caráter de funcionalidade, fundamentado no constante, ininterrupto e rápido processo de fabricação e comercialização de produtos, bem como na oferta de inúmeros serviços públicos e privados. Segundo Furtado e Zanella (2007), as relações do ser humano com o entorno urbano, consequentemente, se complexificaram, tornando-se primordialmente relações práticoutilitárias,ou seja, relações marcadas por uma lógica de consumo.

Nessas trocas mais efêmeras a experimentação de si acontece superficialmente, os sujeitos se relacionam como se estivessem prestando um serviço, ou numa relação de negócios. Em outras palavras, de acordo com Vázquez (1978), em nossa sociedade há primazia de relações prático-produtivas e práticoutilitárias do sujeito com o mundo. Em decorrência, o cotidiano da vida urbana incita que as pessoas não prestem atenção em si, aos seus sentimentos. Da cidade, por sua vez, fica a ideia de ser um espaço impessoal ou então apenas de passagem (Sennett, 2003), ou seja, um local onde o sujeito não consegue expressar suas vontades, seus sentimentos, como se a urbe fosse propriedade de algum dono abstrato e ausente e não espaço de convivência dos que nela habitam.

Entendemos, no entanto, que embora as condições contemporâneas afirmem a possibilidade de existência humana como 
mera passagem, "é facultado ao ser humano, enquanto característica de sua própria humanização, superar o existente e projetarse em direção a devires, instituir relações outras que se diferenciem das relações utilitárias e impessoais que caracterizam a sociedade capitalística" (Zanella e Sais, 2008, p. 683). Essas relações outras seriam relações estéticas, "pautadas em uma sensibilidade que revela a cada um e a todos a riqueza de ser ao mesmo tempo uno e coletivo, de ser expressão e fundamento da realidade. Sensibilidade que se funda na possibilidade de reinvenção da própria existência, problematizada e problematizadora, superação do fato, do dado" (ibid, 2008, p. 683).

Utilizar a arte urbana como forma de modificar os modos de vida propostos pela lógica contemporânea, ou seja, utilizar a arte urbana para criar relações estéticas, significa permitir que emerja a cidade que habita cada pessoa, significa fazer com que os sujeitos se expressem e possam construir novos espaços e possibilidades para si e para outros.

No projeto ArteUrbe a observação realizada é concomitante à intervenção, ambas fundamento do processo de produção de conhecimentos. Partimos de alguns pressupostos iniciais, os quais são reelaborados e redescobertos na própria atividade com o grupo social com o qual trabalhamos. É o encontro da teoria e da prática numa reinvenção de ambas, em que se objetiva interferir a partir dos acontecimentos que o contexto propicia e junto a eles. A construção se dá, concomitantemente, no grupo investigado, na teoria com a qual trabalhamos e nos pesquisadores envolvidos, o que configura o projeto como pesquisa-intervenção.

As rupturas que ocorrem no grupo durante as atividades; ou seja, as relações estéticas que se estabelecem inusitadamente durante a prática do projeto, ou então as brechas que permitem possibilidades para que isso aconteça, são as brechas cruciais para que o pesquisador teça os objetivos, são os momentos em que se oportuniza o acolhimento do sujeito para outras formas de relacionar-se com o mundo, e é justamente nessas brechas de encontro que teoria e prática se fazem juntas. É nesse encontro entre pesquisador, outro com o qual pesquisa e teoria que a psicologia passa a fazer sentido enquanto prática social e re(construção) de conhecimentos.

E isto significa que esta proposição investigativa tem como alvo o movimento, as rupturas que as ações individuais e coletivas imprimem no cotidiano. Como nos diz Rocha (2006), os processos em 
desenvolvimento na pesquisa intervenção produzem permanentemente a realidade na qual cada um de nós e os diferentes grupos são um modo de expressão. Nessa direção, as relações estéticas que o projeto pretende construir com os jovens, para estranhar e modificar suas relações com o mundo encontra nas próprias atividades do projeto canal para sua invenção.

\section{Imagens da cidade em processo}

Para que o projeto de pesquisa/extensão se concretizasse, foi divulgada junto a 6 escolas da rede pública da cidade de Florianópolis/SC circunvizinhas à UFSC, a proposta com o convite aos estudantes para participarem. Após a divulgação, treze jovens se inscreveram via e-mail ou telefone para participar das oficinas. Esses jovens pertenciam a 5 diferentes escolas da rede pública e estavam matriculados no ensino regular. Havia 1 pessoa com 14 anos de idade; 4 com 15 anos; 3 com 16 anos; 3 com 18 e 2 com 20 anos de idade.

Os jovens inscritos foram convidados a realizar uma entrevista antes do início das atividades, entrevistas estas que tiveram como objetivo compreender as motivações deles em participar do projeto, os sentidos que atribuíam às relações entre cidade e arte e suas experiências na urbe. As entrevistas foram gravadas e posteriormente transcritas.

Faziam parte do corpo de coordenadores e pesquisadores do projeto os estudantes de Psicologia: Luana Goulart, Gabriel Bueno, Raquel Alves e Renan Brito, sendo dois bolsistas de extensão pela UFSC e dois bolsistas de IC (PIBIC/UFSC/CNPq. Havia mais um coordenador, grafiteiro profissional e bolsista AT do CNPq, Rodrigo Rizzo, que esteve presente em todos os encontros, assim como os estudantes de Psicologia. Participaram ainda do projeto 2 convidados que ministraram oficinas pontuais: Gabriel Vanini, fotógrafo que coordenou a oficina de fotografia e Vinícius da Costa Ávila, médico cirurgião que coordenou a oficina de stencil. O projeto foi idealizado e orientado pela pesquisadora do $\mathrm{CNPq}$ Andréa Vieira Zanella

A função de cada integrante da equipe durante os encontros variava. Os estudantes de Psicologia filmavam, fotografavam e ajudavam na coordenação de cada encontro, intervindo em qualquer momento que achassem pertinente. Os oficineiros eram os responsáveis por ministrar a parte técnica do encontro, ou seja, cabia a eles instruir sobre as 
linguagens artísticas que estivessem por eles sendo ensinadas. O grafiteiro Rodrigo Rizo, além de ministrar a parte técnica do graffiti, auxiliava nas filmagens e fotografias dos encontros. À orientadora Andréa Zanella, cabia a discussão dos encontros, a coordenação do planejamento das atividades a serem realizadas e a orientação teórica que embasava os estudantes nas discussões e intervenções.

As oficinas foram realizadas às sextas-feiras durante os meses de agosto a dezembro de 2010 e tiveram duração média de três horas cada. Foi realizado o registro fotográfico e audiovisual de todos os encontros e produções do grupo. Nos primeiros meses de 2011, após o término das atividades, foram realizadas novas entrevistas visando compreender as concepções dos jovens em relação à arte na cidade e as possíveis modificações após a participação no projeto.

A seguir são descritas as atividades realizadas em cada encontro com os jovens; condição para a discussão do projeto e de seus resultados.

\section{$1^{\circ}$ Encontro: se conhecendo, conhecendo} a cidade

A primeira oficina teve por objetivos: apresentar as atividades do projeto ArteUrbe e o cronograma de atividades a serem realizadas e a equipe que trabalharia no projeto; e promover a integração dos participantes. Também foi realizada, nessa oficina, uma introdução à temática Cidade, eixo norteador de todo o projeto.

Visando estes objetivos, inicialmente foi realizada uma apresentação do projeto em PowerPoint, momento em que foi informado aos jovens os objetivos e as linguagens artísticas que seriam utilizadas ao longo das oficinas. Em seguida foram realizadas três dinâmicas de grupo visando apresentar e integrar os participantes e "oficineiros". Após essa atividade os jovens foram convidados a desenhar em uma cartolina o que eles entendiam por cidade. Este trabalho visou compreender de que modo significavam a cidade, sua compreensão sobre esta, modos de vivê-la e de habitar esse espaço-tempo.

A proposta dessa atividade partiu da compreensão de que o sentido consiste na “[...] soma de todos os processos psicológicos que são evocados em nossa consciência, graças à palavra [signo]" (Vygotski, 2001, p. 333), sendo sempre uma formação dinâmica, variável e complexa, com várias zonas de estabilidade diferentes. Há zonas mais 
estáveis, conhecidas como significados, mas estes convivem com sentidos outros, vários, decorrentes das condições de cada pessoa, suas trajetórias, as experiências que foram significativas, bem como as condições de produção desses sentidos, social e historicamente datadas.

Após a confecção do desenho os jovens foram convidados a construir uma maquete de material reciclado da cidade de Florianópolis. Interessante observar que mesmo que, apesar da proposta de trabalho ter sido orientada como uma construção conjunta, cada jovem realizou um pedaço dessa maquete sem comunicar-se no grande grupo: constituíram pequenos grupos ou duplas para a realização de uma cidade que tinham em mente. Formaram 3 duplas, um grupo com 3 e outro grupo com 4 pessoas. Vale ressaltar que esse foi o único encontro em que compareceram as 13 pessoas inscritas no projeto. Somente começaram a pensar como organizar as ideias dos grupos em uma única produção quando um dos coordenadores da atividade apressou a construção da maquete em função do tempo restante para concluir o trabalho.

Ao final da construção todos olharam a cidade construída, relataram como foi a realização do trabalho e o que acharam do resultado final. Em seguida foram levantados, junto aos jovens, pontos da cidade a serem visitados na próxima oficina, realizada com a mediação da produção de imagens fotográficas.

\section{$2^{\circ}$ Encontro: a cidade fotografada}

Partindo dos pontos levantados no primeiro encontro, a proposta para a segunda oficina era levar os jovens para um passeio no centro da cidade de Florianópolis para que eles pudessem registrar em imagens fotográficas seus olhares sobre os lugares visitados. A escolha desse recurso assentou-se na compreensão de que:

\begin{abstract}
A fotografia não apenas reproduz o real, recicla-o - um procedimento fundamental numa sociedade moderna. Na forma de imagens fotográficas, coisas e fatos recebem novos usos, destinados a novos significados, que ultrapassam as distinções entre o belo e o feio, o verdadeiro e o falso, o útil e o inútil, o bom gosto e mau gosto. A fotografia é um dos principais meios de produzir esse atributo, conferido às coisas e às situações, que apaga aquelas distinções: “o interessante" (Sontang, 2004, p. 191).
\end{abstract}

Para a realização dessa atividade foram disponibilizadas aos jovens máquinas fotográficas descartáveis. O 
motivo dessa escolha decorreu do fato dessas máquinas possuírem algumas características pertinentes ao objetivo da atividade, a saber: a impossibilidade de se verificar de imediato as fotos que foram tiradas e de apagá-las; o número limitado de 27 poses, o que provoca a escolha deliberada do que fotografar antes de cada click.

Mas essa oficina foi marcada por alguns percalços: aguardamos por 30 minutos a chegada dos jovens na sala que era referência para a realização do Projeto. Após este horário, como o transporte (ônibus) estava atrasado, levamos os jovens para um breve passeio pelo Campus da Universidade, solicitando que registrassem seus modos de olhar aqueles espaços através da fotografia. Nesse dia 8 jovens compareceram ao encontro.

Com a chegada do ônibus fomos para o centro da cidade, sendo que nosso ponto de partida para esse passeio foi o antigo terminal de ônibus urbano. Descendo nesse local, os jovens espontaneamente se subdividiram em grupos por afinidades, a partir das relações que já tinham anteriormente estabelecido entre si, e foram fotografando nos locais previamente escolhidos como foco do olhar e da câmara fotográfica, os detalhes e situações que de certo modo os capturavam.

Foi interessante observar que os jovens se organizaram para fotografar aquilo que consideraram significativo, trocando entre eles alguns comentários, parando, observando, tentando buscar um ângulo para objetivar seu modo de ver a cidade. Apesar das trocas, suas produções foram marcadas pelas escolhas singulares e revelaram que "As imagens são concebidas e materializadas conforme as intenções de seus autores, segundo um filtro cultural e uma determinada visão de mundo" (Kossoy, 2007, p. 104).

Por volta das $16 \mathrm{~h} 30 \mathrm{~min}$ os jovens foram convidados a se dirigir ao nosso ponto de início para retornarmos à universidade. As máquinas foram recolhidas para que as fotos fossem reveladas, material este que serviu de suporte para o trabalho de leitura das imagens e problematização dos olhares sobre a cidade, realizado em momento posterior.

\section{$3^{\circ}$ Encontro: iniciando o graffiti}

A oficina com a linguagem artística do graffiti teve a sua realização em quatro encontros e contou com a mediação de um grafiteiro profissional de Florianópolis e integrante da equipe do projeto ArteUrbe, 
Rodrigo Menegaldo Rizzo. Nesse encontro compareceram 7 dos 13 jovens inscritos no projeto.

O primeiro encontro teve por objetivo apresentar a história desse tipo de arte, desde a sua origem, percorrendo o seu desenvolvimento até chegar ao graffiti hoje. Para ilustrar essa trajetória, foram utilizados livros sobre o assunto, fotos exibidas em data show, imagens disponíveis na internet, recursos esses entremeados com relatos das experiências do grafiteiro. O encontro foi realizado em uma sala de aula e nem mesmo o caráter monótono de um ambiente com a luz apagada foi suficiente para dispersar a atenção dos jovens. Os relatos pessoais de Rizzo foram transmitidos com a força da emoção que ele vivenciou nos momentos em que realizava seus graffitis, o que entusiasmou bastante os jovens, que não desviaram o olhar do grafiteiro.

Dentre os aspectos dessa linguagem artístico-visual, foram apresentados os diferentes modos que o graffiti assumiu no decorrer do tempo, assim como seu desenvolvimento no Brasil e em Florianópolis/SC. A curiosidade dos jovens apontava, principalmente, para as histórias pessoais do grafiteiro quando este contava os enredos dos graffitis que ele havia realizado: as dificuldades, o contexto, os motivos das escolhas dos locais e das criações artísticas entre outros.

\section{$4^{\circ}$ encontro: técnicas do graffiti}

Nesse encontro, ainda ministrado por Rodrigo Rizzo, foi apresentado para os jovens do grupo o instrumento principal de trabalho de um grafiteiro: a tinta em spray. Foi explicado seu funcionamento, as diferentes técnicas de manuseio do material e os diferentes traços que poderiam ser obtidos com a aplicação dessa tinta. O encontro realizou-se a céu aberto e as técnicas puderam ser experimentadas pelos jovens em um muro da universidade, cujo uso foi previamente autorizado para esse fim. A atividade e o contexto geraram empolgação ao grupo, já que foi permitido que experimentassem o spray em uma parede de verdade. O grupo contava com a presença de 9 jovens.

A aplicação das técnicas era feita por um jovem de cada vez. Isso despertou a manifestação da timidez em alguns e o entusiasmo em outros. Aguardavam apreensivos ou ansiosos para a sua vez de inscreverem suas marcas no muro. Após a aplicação das técnicas, foi permitido que eles se expressassem livremente, o que resultou em um muro multicolorido com traços desordenados, porém feitos com 
total liberdade pelos jovens.

\section{$5^{\circ}$ encontro: do papel para o muro}

O encontro foi realizado novamente em sala de aula e o grafiteiro Rodrigo Rizzo era quem dava continuidade ao processo. Aos 8 jovens presentes foi proposto que realizassem, individualmente, desenhos baseados em aspectos da cidade em que vivem. Aquilo que eles retratassem seria posteriormente grafitado no muro em que, na semana anterior, experimentaram o spray. Dentre aspectos positivos e negativos, muitos elementos surgiram nos desenhos: a multiplicidade dos olhares, mesmo que da mesma pessoa, foi evidente.

\footnotetext{
"Cidade sonhada, imaginada, desejada. Cidade planejada, projetada, desenhada. Cidade vivenciada, alterada, cindida. Muitas cidades cabem em uma mesma formação urbana, e suas facetas poderão ser mais bem captadas se o olhar que se lança sobre elas for igualmente múltiplo" (Nascimento e Bitencourt, 2008, p. 32).
}

Após os esboços de cidade projetados no papel, os jovens foram questionados sobre os aspectos que trouxeram à tona. $\mathrm{O}$ sentimento de insatisfação com a urbe foi constante em suas explicações, e surpreendentemente a figura da praia, referência obrigatória nos discursos e imagens veiculados pela mídia que divulgam a cidade de Florianópolis no país e no exterior, sequer apareceu nos desenhos produzidos pelos jovens.

Com a colaboração de todos e suas produções, foi elaborada pelo oficineiro, na lousa, uma imagem de cidade - make say think - juntando os vários fragmentos/desenhos, e a estes outros foram agregados a partir do que coletivamente se considerou necessário.

$\mathrm{Na}$ quarta etapa da oficina de graffiti, os jovens retornaram ao muro em que haviam sido aplicadas as técnicas para, enfim, realizarem um graffiti de fato. $\mathrm{O}$ trabalho foi iniciado pelo grafiteiro/coordenador da oficina, que esboçou um desenho baseado nos rascunhos do make say think realizado pelo grupo. A cidade imaginada/sentida pelos jovens foi projetada no muro, pronta para receber cores e os acréscimos improvisados que surgiram durante $\mathrm{o}$ desenvolvimento da pintura.

A interação dos participantes foi constante, já que a quantidade de cores, apesar de variada, era restrita, o que obrigava a troca de latas de spray entre eles durante a confecção. Novamente se revezava entre pessoas mais extrovertidas ou mais discretas a interação dos jovens com a pintura. 
O resultado final retratava uma cidade colorida carregada de uma multiplicidade de elementos, oriundos de pessoas que habitam a mesma cidade no mapa, mas diferentes na significação que sobre esta produzem. Dentre esses elementos encontram-se: meios de transporte (avião, ônibus), banco de praça, árvore, moradias no morro, fezes na calçada, pipa no céu, prédios, entre outros.

\section{$6^{0}$ Encontro: oficina de lambe- lambe}

O lambe-lambe, ou lambe apenas, é um pôster artístico de tamanho variado que é colado em espaços públicos. O pôster pode ser criado individualmente ou produzido através de foto copiadora, sendo geralmente colado com cola de polvilho (forma utilizada na oficina). Há diversas utilizações do lambe (divulgações de serviços, propagandas, informes), porém a utilização artística é que o enquadra na categoria das novas linguagens da arte urbana.

A oficina de lambe-lambe teve duração de dois encontros e foi coordenada por Gabriel Bueno (integrante da equipe do projeto). $\mathrm{O}$ objetivo consistiu em apresentar essa forma de intervenção artística para os jovens como meio de intervir na estética da cidade, ensinar a produção e utilização do material para depois aplicá-lo.

Aos 6 jovens presentes nesse dia foi proposto que desenhassem com canetas hidrocor em folhas de papel sulfite ilustrações que quisessem aplicar no muro anteriormente grafitado. Os desenhos foram produzidos com rapidez e o resultado foi um vasto número de ilustrações, o que levou à tomada de uma decisão coletiva: cada jovem deveria escolher apenas algumas de suas produções para serem coladas no muro, para não encobrir demasiadamente a área grafitada.

O processo de produção da cola foi ensinado passo a passo na oficina e os jovens foram informados sobre a importância e a tradição da produção caseira da cola. Seu produto é o resultado da mistura de polvilho doce ou azedo (desses adquiridos em mercados ou mercearias) e água fervente. Cabe ressaltar que a cola utilizada por eles foi produzida por Raquel Alves (integrante da equipe do projeto) em sua própria casa no dia anterior, já que a necessidade de um fogão dificultou a sua execução durante a oficina.

O custo reduzido é um dos benefícios da produção caseira da cola, porém existe aí outro motivo para sua utilização: o fato de produzirmos algo que 
poderia ser comprado em qualquer esquina provoca uma quebra na rotina e no costume do imediatismo dos produtos industrializados. A relação com o produto (ao contrário do que ocorreria se a cola fosse comprada pronta) proposta na oficina, não foi uma relação de praticidade e utilitarismo, ao contrário, tornou-se um momento de entrar em contato, de estabelecer uma relação mais sensível com a possibilidade de produção de algo necessário. É como a provocação de um encontro sensível entre sujeito e objeto, momento em que ocorrem trocas e transformações, e onde existe brecha para a experimentação de uma relação estética, de uma experimentação do novo. A produção da cola contrapõe-se, assim, à simples obtenção de um produto, é parte do processo artístico e de constituição do sujeito que a cria e por seu intermédio se recria.

Fomos então praticar o que havia sido ensinado na oficina. Aplicamos as técnicas no mesmo muro em que o graffiti foi produzido, ou seja, os lambes foram acrescentados a outra produção artística, como proposta de interação entre duas formas de linguagens artístico-visuais. Foi sugerido que a cola e os desenhos excedentes fossem levados pelos jovens para que pudessem utilizar onde desejassem.

\section{$7^{\circ}$ Encontro: olhar estético}

No inicio desse encontro, foi solicitado aos jovens que entrassem na sala um de cada vez com os olhos vendados, localizassem as cadeiras (dispostas em círculo) através do toque e se sentassem. O grupo contava com a presença de 5 das 13 pessoas inscritas inicialmente.

A eles foram entregues objetos distintos, os quais deveriam ser tateados para que pudessem conhecer as suas características e descrevê-las aos colegas, obedecendo a uma regra: mesmo que a pessoa que tateava reconhecesse o objeto, não deveria dizer seu nome nem as suas funções, apenas suas características. Aos demais (que também estavam de olhos vendados) caberia adivinhar o objeto que estava sendo descrito. Após os jovens exercitarem seus sentidos, retiraram as vendas dos olhos e foi dado início à segunda parte da atividade. Com a coordenação de Raquel Alves (integrante da equipe), foram apresentadas várias imagens de obras de arte, as quais foram analisadas conjuntamente. Ao grupo foram apresentados diversos aspectos dessas obras: técnicas de pintura utilizadas pelos artistas, contexto histórico em que as 
pinturas foram realizadas, características referentes aos estilos dos autores, etc. Em seguida foi sugerido que cada pessoa escolhesse as obras que mais lhes chamasse a atenção, apresentasse ao grupo e discorresse sobre quais aspectos influenciaram suas escolhas.

Esse encontro teve por objetivo exercitar a percepção da realidade a partir de outros sentidos e descrevê-la de outra maneira que não a habitual. A análise de obras de arte, por sua vez, possibilitou aos jovens um olhar diferenciado sobre aquelas imagens, trazendo a eles elementos que estão implícitos nessas e outras obras e muitas vezes inacessíveis aos leigos, mas que uma vez explicitados trazem outra noção sobre o assunto: demonstram a complexidade e as minúcias que existem nas produções estéticas, ricas em sentidos que podem engendrar vivências estéticas.

\section{$8^{\circ}$ Encontro: fotografia em foco}

A oficina de fotografia, ministrada pelo fotógrafo Gabriel Vanini, teve por objetivo transmitir noções técnicas de fotografia, de enquadramento, iluminação, foco, possibilitando assim que os jovens desenvolvessem um olhar diferenciado sobre o assunto. Foram abordados, também, aspectos históricos da fotografia e características básicas de funcionamento de câmaras fotográficas. Esse foi um encontro com caráter mais técnico, pouco interativo: não foi proposto aos jovens produções. $\mathrm{O}$ número de jovens permanecia reduzido, sendo que nesse dia compareceram, novamente, 5 pessoas.

Ao final, novamente foram distribuídas câmaras fotográficas descartáveis com 27 poses para que os jovens levassem consigo e registrassem/produzissem imagens da cidade, dessa vez a partir de um olhar mais técnico sobre fotografia.

\section{$9^{\circ}$ Encontro: oficina de estêncil}

O Estêncil é uma técnica utilizada para aplicar um desenho ou ilustração: consiste em cortar ou perfurar uma folha de material resistente (o material mais utilizado é a chapa de radiografia), resultando em um molde com o preenchimento do desenho vazado por onde passará a tinta. Pode-se utilizar para pintar diversos objetos, mas sua utilização nas ruas da cidade o transforma em uma técnica da arte urbana.

A oficina de estêncil, coordenada por Vinicius da Costa Ávila, artista que como ocupação principal exerce a medicina e é reconhecido 
profissionalmente na cidade, tinha por objetivo ensinar a técnica de produção do estêncil e sua aplicação. Aos jovens foram distribuídas revistas diversas para que eles escolhessem ilustrações que lhes chamassem a atenção e se inspirassem em relação à temática dos estêncils que criaram.

O número de pessoas, que era oscilatório no grupo devido ao caráter de não obrigatoriedade de presença, superou a média nesse dia. A sala cheia novamente (12 jovens) gerou um movimento intenso, porém fluido: a boa comunicação e solicitude do oficineiro fizeram com que o grupo trabalhasse em sintonia e leveza, e possibilitou a impressão de que os ponteiros do relógio corriam.

Entre desenhos simples e complexos, a execução dos moldes levou mais ou menos tempo e as escolhas das ilustrações não obedeceram a um padrão: borboletas, fadas, pessoas famosas, autoretrato, entre outros, são exemplos das produções que surgiram.

Quando prontos, os estêncils foram aplicadas em tapumes de madeira dentro da própria sala, já que a chuva impossibilitava que o grupo fosse ao muro utilizado no projeto.

\section{$10^{\circ}$ Encontro: fechamento}

No último encontro com o grupo foram disponibilizadas aos 4 jovens presentes as fotos reveladas das câmaras que haviam sido recolhidas no encontro anterior para discussão e reflexão sobre as imagens produzidas. As fotos foram espalhadas ao chão de modo aleatório, e foi solicitado aos jovens que encontrassem as que eram de sua autoria. As fotos ficaram realmente fascinantes: as imagens traziam bom gosto, criatividade e qualidade em sua maioria.

Foi pedido para que cada um comentasse a própria produção: os locais escolhidos, os motivos das escolhas, as fotos que mais gostaram. Ou seja, que falassem um pouco do próprio trabalho. $\mathrm{O}$ momento foi marcado pela descontração e surpresas com as fotografias próprias e alheias.

Após as reflexões sobre as fotos, foram realizadas duas dinâmicas de grupo. A proposta da primeira dinâmica foi fazer uma homenagem às pessoas que permaneceram até o final dos encontros e estavam ali presentes. Para isso foi feita uma atividade com dobraduras de papel, acompanhada de um discurso de agradecimento ao grupo. A segunda trazia a proposta de que fossem coladas com fita 
crepe folhas sulfites nas costas de todos os que ali estavam presentes. Foi proposto então que circulassem pelo espaço e escrevessem recados nas folhas alheias. Surgiram assinaturas, frases, recados, desenhos, entre outros.

Ao final do encontro foi oferecido um lanche para celebrar o processo vivenciado ao longo das oficinas, possibilitando um momento de confraternização aos participantes.

\section{Múltiplos olhares sobre a mesma cidade}

Os jovens que participaram do projeto habitavam a mesma cidade, porém as cidades que habitavam neles eram nitidamente diferentes. Quando foi solicitado que a expressassem, foi visível que a urbe não vinha só: estava diluída na historia de vida de cada um. As cidades apresentadas pelos jovens eram diferentes, únicas e particulares, e quase nenhuma delas se assemelhava com as maravilhosas imagens da Ilha de Santa Catarina veiculadas na mídia. Curiosamente, nos diversos momentos em que foram solicitados desenhos ou fotografias da cidade, a imagem da praia sequer surgiu. A Florianópolis dos jovens que ali estava divergia da Florianópolis dos cartões postais.
A ausência da figura da praia nas representações da cidade de Florianópolis foi no mínimo intrigante, e os jovens foram questionados sobre esse fato. No entanto, a resposta veio com pouco entusiasmo, como se a praia estivesse distante do dia-a-dia deles, distante dos sentidos da cidade para eles. A praia não era, definitivamente, um local de convívio para aquelas pessoas, pois não a usufruíam. Em decorrência, a praia não era presente na cidade deles.

Apesar de apresentarem alguns pontos em comum, veio à tona a cidade que é obra singular, apropriada, incorporada e traduzida conforme a linguagem de cada sujeito. Aquela que está escondida em cada um e que raras vezes encontra oportunidade de emersão e acolhimento no espaço urbano.

Surgiram nas imagens pelos jovens produzidas diversas marcas típicas da cidade: locais de convívio, dejetos e objetos tipicamente urbanos. Dentre essas marcas estavam presentes: prédios, antenas, aviões, carros, ônibus, trens, favelas, fezes de cachorro, sacos de lixo, pichações, baratas, ratos, pipas, bancos de praça, calçadas, pessoas, árvores, hidrantes de rua e bueiros. Além disso, surgiram manifestações contra o elevado preço da tarifa de ônibus e, única representante dos cartões postais da cidade de Florianópolis, 
a ponte Hercílio Luz.

Contudo, cada imagem dessas, ainda que presentes em diferentes contextos urbanos, (re)surgiu com uma particularidade original. São traços, formas, cores e conteúdos próprios e que jamais poderão ser encontrados daquela maneira nos espaços da cidade. É a cidade de cada um. Apesar de haver objetivamente pontos em comum nas imagens produzidas pelos jovens, os espaços urbanos expressados nos mostram que ele não existe em forma única, muito menos estática. A singularidade de cada jovem (re)monta uma nova cidade a cada caminhar, a cada minuto inventado, vivido. A construção da cidade, por conseguinte, é feita diariamente, a partir do repertório de vida de cada habitante da urbe, a partir dos modos de apropriação e objetivação, ao mesmo tempo singulares e coletivos.

$\mathrm{O}$ mundo em que vivemos fala de diferentes maneiras, e essas vozes participam do diálogo da vida. A unidade da experiência e da verdade do homem é polifônica. Dialogismos e alteridade, como nos diz Jobim e Souza (2003), constituem as características, essenciais e necessárias, a partir das quais o mundo pode ser compreendido e interpretado de muitas e diferentes maneiras, tendo em vista seu permanente estado de mutação e inacabamento.

Cada aspecto da cidade é imediatamente transformado ao ser percebido/apropriado pelos seus citadinos, percorrendo um caminho de mutação. Penetra seus corpos pelas vias dos sentidos e funde-se com a experiência do sujeito, sendo filtrada, acrescida e transformada em uma obra de arte: a cidade de cada um.

Essa singularidade dos sujeitos urbanos que (trans)formam novas cidades é construída dentro e a partir do próprio espaço urbano. Quando essa relação de transformações se dá no plano concreto (o de construção da urbe), à cidade são devolvidos aspectos que já foram dela em algum momento, porém são transformados a partir da cidade de cada habitante. Ao construir, transformar, se experimentar na cidade, este demonstra à cidade aquilo que dela encarna e que se faz carne.

O cimento, o asfalto, os tijolos, estão sedimentados com emoções, misturados a histórias, sonhos, conquistas. Cada pedaço urbano é um aglomerado disso tudo e cada pessoa é um aglomerado de sentidos que produziu e se apropriou a partir do contexto em que vive, na sua história tecida na interlocução de diversas histórias outras, de variados tempos e condições. Cada personagem dessa cidade é ao mesmo tempo construído e construtor 
da própria urbe. Possui as suas ruas próprias, com suas próprias cores, com seus próprios tons, com sua própria música, não necessariamente reconhecidas e valorizadas.

Ao encontrar espaço para fazer emergir essas experiências singulares, redimensionam-se as possibilidades de relações com a cidade: relações estéticas, sensíveis com o entorno, fundantes das possibilidades de se ver como pessoa ativa na construção do contexto em que habita e que o habita.

No entanto, se o trânsito impiedoso de ideias desgovernadas disparadas pela cidade dominante e por vezes opressiva estrangula as vias singulares, se o cinza predominante das ruas encobre as cores únicas e belas de cada pessoa, se o som desarmônico e invasivo da vida urbana abafa a música de composição própria, a pessoa morre em vida, não participa da construção da cidade que habita, não expressa a sua singularidade, não encontra possibilidade de se descobrir a partir do contexto em que vive. "A partir daí, seria preciso perguntar-se de que maneira, no interior dessa megamáquina de produção de subjetividade, surgem novas modalidades de se agregar, de trabalhar, de criar sentido, de inventar dispositivos de valorização e de autovalorização (Pelbart,
2003, p. 21)".

A maneira como os jovens participantes do projeto significavam a cidade, conforme já foi citado, não convergia com as imagens de Florianópolis difundidas na mídia. Apesar dos olhares serem divergentes ao olhar da mídia, não cabe o julgamento de valor, ou seja, para os pesquisadores não haveria olhar mais coerente ou menos, olhar correto ou incorreto. A questão principal gira em torno de que maneira fazer esses olhares emergirem e se constituírem como (re)inventores ativos na urbe. Isso porque permitindo, significando e analisando essas maneiras outras de olhar, seus modos de subjetivação e seus processos de constituição, abrem-se possibilidades de transformação dessas significações, de fazer parte do processo de fazer cidade fazendo-se na cidade.

As relações estéticas, sendo uma forma sensível de se relacionar com o mundo, possibilitam engendrar processos de ressignificação da urbe, e desse movimento decorre um maior contato consigo mesmo e com as próprias escolhas. O projeto ArteUrbe teve como foco justamente as significações dos jovens sobre a cidade e, na sua esteira, a própria noção deles naquele espaço, o reconhecimendo de sua condição de 
produto e produção. A partir das atividades propostas objetivou-se constituir possibilidades de (re)significação de si e do espaço, de perceber a indissociabilidade de ambos na (co)nstruçao da cidade e dos modos de ali habitar.

Negligenciar as diversificadas maneiras de olhar e transitar a urbe em obediência às normas estabelecidas é o mesmo que obscurecer o que a cidade produz, é querer tornar invisível o que a própria sociedade cria, diminuindo as possibilidades de seus habitantes a (re)criarem ativamente e a partir dela se (re)constituírem.

São como diretrizes sociais que obliteram a possibilidade de expressão de cada pessoa e de sua participação na reinvenção da urbe. E é devido a essa cidade de formas dominantes que a reinvenção das relações com a urbe se apresenta como desafio.

\section{Referências}

Canevacci, Massimo (1993) A cidade polifônica: ensaio sobre a antropologia da comunicação urbana. São Paulo/SP: Ed. Studio Nobel.

Calvino, Ítalo (1990) As cidades invisíveis. São Paulo/SP: Ed. Companhia das Letras. Furtado, J. e Zanella, A. Artes visuais na cidade: relações estéticas e constituição dos sujeitos. Psicologia em Revista, 13 (2), 309-324.

Kossoy, Boris (2007) Os tempos da fotografia: o efêmero e o perpétuo. São Paulo: Ed. Ateliê Editorial.

Sennett, Richard (2003) Carne e pedra: o corpo e a cidade na civilização ocidental. São Paulo: Ed. Record. 3

Sontang, Susan (2004) Sobre Fotografia. São Paulo/SP: Ed. Companhia das Letras.

Vázquez, Sanchez (1978) As ideias estéticas de Marx. Rio de Janeiro/RJ: Ed. Paz e Terra.

Vygotsky, L. S (2001) Psicologia da arte. São Paulo/SP: Ed. Martins Fontes.

Zanella, A. e Maheirie, K. (Orgs) (2010), Diálogos em Psicologia Social e Arte. Curitiba/PR: Ed. Curitiba.

Zanella, A. e Sais, A. (2008) Reflexões sobre o pesquisar em Psicologia como processo de criação ético, estético e político. Análise Psicológica, Lisboa, v. 26, n. 4, out. 2008. Disponível em http://www.scielo.org

Renan De Vita Alves de Brito. Graduando em psicologia pela UFSC, bolsista de iniciação científica pelo programa PBIC/UFSC/CNPq. E-mail: renanbrito4@yahoo.com.br 


\section{Polis e Psique, Vol.2, n.1, 2012 Página|62}

Andréa Vieira Zanella. Professora do Departamento e do Programa de pósgraduação em Psicologia da UFSC, bolsista em produtividade do CNPq. Email: azanella@cfh.ufsc.br

Endereço: NUPRA - Depto de Psicologia Centro de Filosofia e Ciências Humanas da Universidade Federal de Santa Catarina - UFSC Campus Universitário - Trindade CEP 88.040-970 - Florianópolis Santa Catarina - Brasil 